\title{
Proceedings of the 16th conference of the International Work Group for Palaeoethnobotany, Thessaloniki 2013
}

\author{
Soultana M. Valamoti • Felix Bittmann
}

Received: 14 November 2014/ Accepted: 18 November 2014/Published online: 9 December 2014

(C) Springer-Verlag Berlin Heidelberg 2014

This volume of Vegetation History and Archaeobotany comprises a collection of papers presented at the 16th conference of the International Work Group for Palaeoethnobotany, held at the Research Dissemination Centre (KEDEA) of the Aristotle University of Thessaloniki (Greece) between June 16th and 22nd 2013. The conference was organised under the auspices of the School of History and Archaeology of the Aristotle University of Thessaloniki, the Municipality of Thessaloniki, the Hellenic Ministry of Education and Religious Affairs, Culture and Sports and the Hellenic Ministry of Rural Development and Food. The Museum of Byzantine Culture hosted the official dinner of the conference. The following institutions financially supported the conference: the Research Committee of the Aristotle University of Thessaloniki, the Institute of Aegean Prehistory, Foglip-ERC, the Ministry of Rural Development and Food, and Piraeus Bank.

Various other sponsors supported the conference with donations in kind (gifts and food/drink): Agrino, Apivita, Archaeological Museum of Thessaloniki, Babatzim wines, Claudia Papagianni wines, Creta Carob, Gerovassileiou wines, Haitoglou, Holomon herbs, Ianos, I Kathimerini, Korres, Kyr Yianni wines, Ligas wines, Masticha Shop, MIET (National Bank of Greece Cultural Foundation), Mylelia, Pantopoleion tis Thessalonikis, Psichalos publications, Rayan

\section{S. M. Valamoti}

Department of Archaeology, School of History and

Archaeology, Aristotle University of Thessaloniki,

54124 Thessaloníki, Greece

e-mail: sval@hist.auth.gr

\section{F. Bittmann ( $\square)$}

Niedersächsisches Institut für historische Küstenforschung,

Viktoriastr. 26/28, 26382 Wilhelmshaven, Germany

e-mail: bittmann@nihk.de
Foods, Tea-Routes, Thessaloniki Chef's Association, Thessaloniki Hotels Association, University Studio Press, Vaeni wines, Vivlia Chora wines, Yiam. In times of financial hardship their help has been invaluable.

This is the first time an IWGP conference has been organised in Greece, where archaeobotany was initiated by German, Dutch and British colleagues, like Maria Hopf, Helmut Kroll, Willem van Zeist, Sytze Bottema, Glynis Jones, Jane Renfrew and James Greig, most of whom were among the pioneers of archaeobotany worldwide. These people sowed the seeds of archaeobotany in Greece as members of national archaeological school missions in various parts of the country, in those early days when archaeology was 'losing its innocence' as David Clarke epitomised the arrival of New Archaeology (Clarke 1973). Among the pioneers, colleagues such as Glynis Jones and Helmut Kroll not only 'saved seeds' (Jones et al. 1982) and broadened the horizons of Greek archaeobotany but, perhaps most significantly trained indigenous archaeologists into becoming the first native archaeobotanists. Thus, the 16th IWGP held in Thessaloniki (the second Mediterranean city to host an IWGP after Girona in Spain 2004) would simply not have happened without the work of these teachers and practitioners of archaeobotany.

The conference went officially global this time, providing a podium to papers from regions not traditionally represented in the preceding IWGP meetings. Presentations on Inuit archaeobotany, South African hunter-gatherer survival strategies, Chinese burial offerings, Japanese prehistoric rice growing and consumption, and Argentinian early cultivation and food processing demonstrate the wide geographical range represented by the current IWGP. Various challenges had to be dealt with during the organisation of the conference including a large number of submitted oral presentations and posters, and a host country in deep financial 
crisis. During the five days of talks and posters, a tightly packed programme presented an organisational challenge and probably a strain to what one can absorb during a conference. Yet, it was decided neither to have parallel sessions nor to cut out any of the sessions proposed by many organisers on special thematic fields such as 'Stable isotopes in plant remains', 'Food globalization in prehistory across Eurasia', 'Dispersal of cultivated plants: the origin and early spread of naked wheats', 'The role of wild foods amongst early farmers and late foragers' and 'Plant archaeogenetics and archaeogenomics'.

In addition to the laboratory session a special identification workshop on naked cereals took place, organised by Stefi Jacomet. Another workshop took place where Spätzle were prepared in the traditional way (organised by Barbara Zach, Hans-Peter Stika and Moritz Hallama), putting archaeobotany into action. The dish prepared was a Swabian speciality consisting of spelt wheat noodles (Spätzle) and lentils, ingredients frequently occurring in European Bronze Age archaeobotanical data sets.

In total, nearly 270 participants attended the conference (Fig. 1). The oral presentations totalled 98 while 164 posters were presented. For the special issue 50 papers have been announced, 27 papers were finally submitted of which 20 were accepted for publication after peer-reviewing.

The Original Articles (15) can be divided into contributions on plant use, economy and methodological aspects spanning the Neolithic through to the Iron Age (HartmannShenkman et al.; Antolin et al.; Valamoti; Kubiak-Martens et al.; Martin; Pagnoux et al.), on more methodological and integrated aspects including taphonomical problems, geoarchaeology and phytoliths as well as pollen (Pelling et al.; Petô et al.; García-Granero et al.; Vandorpe and Wick). These are followed by contributions focussed on plant foods (cultivation, transformation, offerings) in South America and China partly taking into account ethnobotanical aspects (Lema; Capparelli et al.; Jiang et al.) and two papers on medieval sites and economy from Ireland and Siberia (McClatchie et al.; Korona).

Four Reviews give overviews and the state of the art of new glume wheat in France (Toulemonde et al.), advances in aDNA of plant remains (Brown et al.), stable isotopes (Fiorentino et al.) and the history of Taxus in southwest Europe (Uzquiano et al.—communicated by C. Bakels). The volume is completed by a contribution on medieval finds of Smyrnium olusatrum in the Netherlands (Brinkkemper).

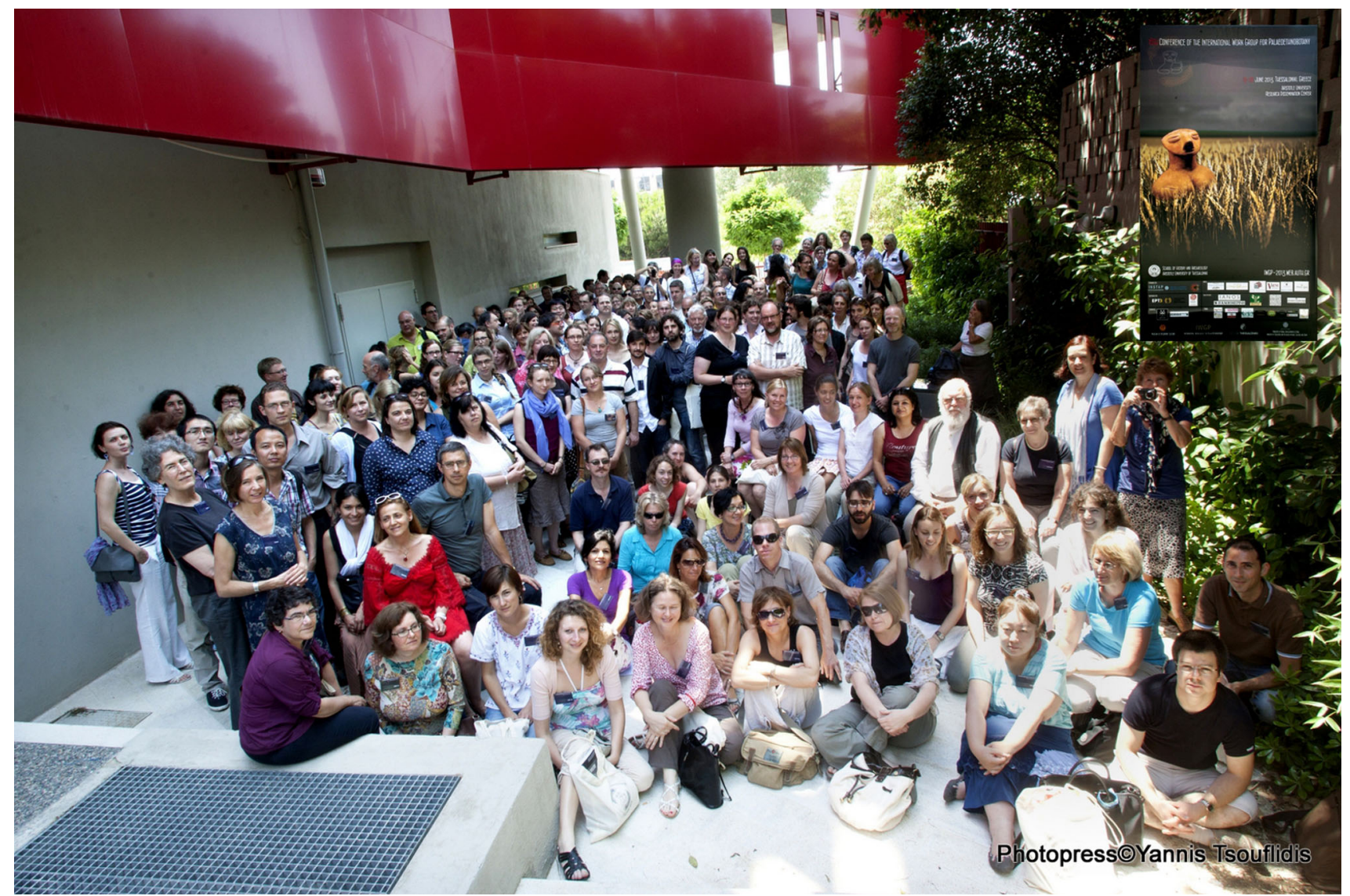

Fig. 1 16th IWGP participants at the KEDEA premises. Photo courtesy of Giannis Tsouflidis@ 
Thus, topics of this volume include early farming, ancient food and the role of wild plant resources, regional syntheses or analyses focusing on single species, case studies, integration of archaeobotanical data and methodological issues including frontline research methods such as DNA and isotopic analyses.

The publication of this volume has been generously funded by the Institute for Aegean Prehistory (INSTAP) and we wish to express our deepest thanks to INSTAP and Karen Vellucci for all the help provided in the process as well as to Judith Terpos and Margaret Dei- gnan from Springer who helped with all the technical questions.

A large number of reviewers greatly assisted in the preparation of this issue; with their perceptive, critical comments they determined the selection of the submitted manuscripts and contributed towards improving them. They are gratefully acknowledged below. Our sincere thanks are due to James Greig and John Daniell for their thorough copy/ language editing of the manuscripts, guaranteeing a high language standard of the scientific papers not only for this volume but also during many years previously.

\section{Acknowledgement to referees}

\begin{tabular}{lll}
\hline Akeret, Örni; Basel, CH & Heiss, Andreas; Wien, A & Nesbitt, Mark; London, UK \\
Allaby, Robin; Warwick, UK & Jacomet, Stefanie; Basel, CH & Rovner, Irwin; Raleigh, USA \\
Antolín, Ferran; Basel, CH & Jones, Glynis; Sheffield, UK & Ruas, Marie-Pierre; Paris, F \\
Bakels, Corrie C.; Leiden, NL* & Jones, Martin; Cambridge, UK & Schwarz, Anton; Innsbruck, A \\
Barboni, Doris; Aix-en-Provence, F & Kohler-Schneider, Marianne; Wien, A & Stika, Hans-Peter; Stuttgart, D* \\
Bittmann, Felix; Wilhelmshaven, D* & Kozakova, Radka; Praha, CZ & Thiébault, Stéphanie; Paris, F \\
Bogaard, Amy; Oxford, UK & Kreuz, Angela; Wiesbaden, D & Valamoti, Soultana M.; Thessaloniki, GR* \\
Bouby, Laurent; Valbonne, F & Kroll, Helmut; Kiel, D & Van Haaster, Henk; Zaandam, NL \\
Brinkkemper, Otto; Amersfoort, NL* & Kubiak-Martens, Lucy; Zaandam, NL & White, Chantel; Notre Dame, USA \\
Butler, Ann; Surrey, UK & Lightfoot, Emma; Cambridge, UK & Wiethold, Julian; Metz, F \\
Charles, Michael; Sheffield, UK & Livarda, Alexandra; Nottingham, UK* & Willcox, George; Jalès, F \\
D’Andrea, Cathy; Burnaby, CDN & Madella, Marco; Barcelona, E & Wright, Patti J.; St. Louis, USA \\
Ertuğ, Füsun; İznik Bursa, TR & Mariotti Lippi, Marta; Firenze, I & Yang, Xiaoqiang; Beijing, CN \\
Fairbairn, Andrew; Queensland, AUS & Mercuri, Anna Maria; Modena, I & Zach, Barbara; Bernbeuren, D \\
Grillo, Oscar; Cagliari, I & Milanesi, Claudio; Siena, I & Zhang, Jianping; Beijing, CN \\
\hline
\end{tabular}

* Multiple reviews

\section{References}

Clarke DL (1973) Archaeology and the loss of innocence. Antiquity 47:6-18

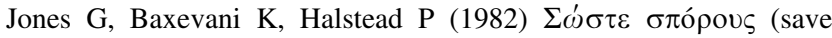
seeds). Anthropologika 3:86-87 